\title{
Jumping translocations of $1 q$ in donor cell-derived myelodysplastic syndrome after cord blood transplantation: Case report and review of the literature
}

\author{
TOSHINORI KONDO ${ }^{1}$, TAIZO TASAKA ${ }^{2}$, RISA SHIMIZU ${ }^{1}$, KIYOHITO HAYASHI ${ }^{1}$, SEIKO YAMADA ${ }^{1}$, \\ HIROFUMI FUKUDA ${ }^{1}$, TADASHI HIROSE ${ }^{1}$, ASAKO TAKEUCHI ${ }^{1}$, FUMINORI SANO ${ }^{1}$, \\ HIROTOSHI TOKUNAGA ${ }^{1}$, YOSHIKO MATSUHASHI ${ }^{1}$ and HIDEHO WADA ${ }^{1}$ \\ ${ }^{1}$ Department of Hematology, Kawasaki Medical School, Kurashiki, Okayama 701-0192; \\ ${ }^{2}$ Department of Transfusion Medicine and Cell Therapy, Saitama Medical Center, \\ Saitama Medical University, Kawagoe, Saitama 350-8550, Japan
}

Received December 11, 2018; Accepted July 3, 2019

DOI: $10.3892 /$ mco.2020.1995

\begin{abstract}
Donor cell-derived leukemia and myelodysplastic syndrome (DCL) is a rare complication in patients after allogenic stem cell transplantation (SCT). Since 1971, numerous cases of DCL have been reported, but the detailed mechanisms of DCL are still unclear. A patient with jumping translocations (JTs) of 1q in umbilical cord blood donor cell-derived myelodysplastic syndrome (MDS), which likely occurred due to genetic alterations of TET2 and ASXL1 after cord blood transplantation (CBT), was examined in this study. Previously reported DCL cases after CBT that focused on the cytogenetic and molecular characteristics of these patients and patient outcome were reviewed. A total of 30 cases of DCL after CBT were identified between 2005 and 2018. The median time from CBT to the development of DCL was 16 months. The number of patients with DCL who were diagnosed with acute myeloid leukemia (AML) and MDS was 19 and 8, respectively. JTs were frequently observed in 5 of 27 DCL patients who had cytogenetic abnormalities, including our patient. Molecular abnormalities were described in 7 of the cases, and the most frequent abnormality was an NPM1 mutation. Other gene mutations that were usually found in de novo MDS or AML were observed in JT-DCL after CBT. From these results, chromosomal abnormalities such as JTs that occur subsequent to genetic alterations were seemed an important mechanisms underlying DCL onset in patients after CBT. Further molecular analyses regarding the genetic alterations of JTs are required to
\end{abstract}

Correspondence to: Dr Toshinori Kondo, Department of Hematology, Kawasaki Medical School, 577 Matsushima, Kurashiki, Okayama 701-0192, Japan

E-mail:kondot@med.kawasaki-m.ac.jp

Key words: jumping translocation, myelodysplastic syndrome, cord blood transplantation, donor cell-derived leukemia, genetic mutation understand the pathogenesis of umbilical cord blood-derived JT-DCL.

\section{Introduction}

Donor cell-derived leukemia and myelodysplastic syndrome (DCL) is a rare but crucial complication in patients after allogenic stem cell transplantation (SCT). Since the first report of DCL was published in 1971, numerous cases of DCL have been reported (1-9). Previous cases of DCL have been reported with all stem cell sources, including peripheral blood stem cells $(2,9,10)$, bone marrow $(2,9,11)$, and umbilical cord blood $(5,9,12-14)$. Umbilical cord blood is recognized as an alternative stem cell source for transplantation, and since 2005, some cases of DCL after cord blood transplantation (CBT) have been reported to have poor prognoses (12-15).

Possible mechanisms for DCL that have been explored include preleukemic clones already present in the graft at the time of transplantation $(7,8,16)$, telomere shortening in engrafted donor cells (17), the effects of residual agents of conditioning chemotherapy or radiation on infused graft cells and/or stromal elements (18), and recipient stromal cells that may drive the development of malignancy and impaired immune surveillance in the posttransplantation period (7). However, the detailed mechanisms of DCL are still unclear, and if we can clarify the mechanism of umbilical cord blood stem cell-derived leukemia, it may explain the mechanism of leukemogenesis. Recently, some reports of genetic alterations in DCL by whole genome or target sequencing have been published (19). These results suggest that some DCL cases develop due to an accumulation of the same genetic mutations as de novo acute myeloid leukemia (AML) or myelodysplastic syndrome (MDS). However, it is not sufficient to clarify the whole picture of genetic alterations in DCL; the accumulation of a genetic mutation profile of DCL cases is needed.

Jumping translocations (JTs) are a rare type of cytogenetic abnormality detected in various types of leukemia but infrequently in patients with MDS. JTs occur when a segment of a particular chromosome is duplicated and inserted into several 
other chromosomes, resulting in multiple gains of the chromosomal segment via multiple translocations and a possible loss of segments in the recipient chromosomes $(20,21)$. The most commonly observed JT involves 1q as the donor chromosome segment and is referred to as a JT of 1q. Previously, JT of 1q had been identified in de novo MDS or AML (20-22), and a few cases had been reported in DCL. The prognosis of JT of $1 \mathrm{q}$ is poor, and the translocation is associated with a high risk of progression to AML or treatment resistance $(23,24)$.

Here, we report a case of JT of 1q in umbilical cord blood donor cell-derived MDS that most likely occurred due to genetic alterations after CBT. The patient achieved complete remission (CR) after treatment with azacytidine and a second CBT. Therefore, we reviewed 30 previously reported cases of DCL after CBT, and we described the cytogenetic and molecular characteristics of the patients and patient outcome.

\section{Case report}

Patient and donor. A 49-year-old female with AML without maturation (FAB M1) was treated with induction and consolidation chemotherapies, achieving CR in our hospital. Two years later, she relapsed and had bone marrow and skin lesions. The myeloblasts were positive for CD33 and CD34, and negative for $\mathrm{B}$ and $\mathrm{T}$ lymphoid lineage markers by flow cytometric analysis. Cytogenetic analysis revealed a normal female karyotype. She achieved a second CR after induction chemotherapies and consecutively underwent allogenic CBT after a reduced intensity conditioning regimen with fludarabine (25 mg/m²/day, 5 days), cytarabine (3,000 mg/m²/day, 4 days), melphalan (70 mg/m²/day, 1 day) and 6 Gy of total body irradiation. Prophylaxis for graft vs. host disease (GVHD) included the use of tacrolimus until 248 days after CBT $($ day+248). The graft source was a female donor with human leucocyte antigen class I, A (HLA-A) and an HLA-DRB1 split-allele mismatch. Favorable hematological recovery was observed on day +28 , and bone marrow examination on day +48 showed complete chimera of the donor. Acute GVHD of the skin (stage 4, grade IV) was observed on day+35 and was ameliorated by treatment with methylprednisolone. From day +277 , she developed anemia that became gradually worse. Bone marrow examination on day +417 revealed normocellular marrow with $18.6 \%$ myeloblasts. Morphologic dysplasia, such as micromegakaryocyte and megaloblastoid changes in the erythroid lineage, was observed. The blasts were positive for CD7, CD13 and CD56 and negative for B and other T lymphoid lineage markers by flow cytometric analysis. Cytogenetic analysis revealed a complex karyotype including JT of $1 \mathrm{q}$ abnormalities: 46, XX, der(16)t(1;16)(q21;q22)ins(16;?)(q22;?) [18/20], 46, XX [2/20]. Additionally, marrow blood chimerism was analyzed by using the short tandem repeat (STR) method at day +417 , and at day+441, the donor type was maintained, and the marrow HLA was the donor type. According to these results, the patient was diagnosed with $\mathrm{JT}$ of $1 \mathrm{q}$ in donor cell-derived MDS with excess blasts.

CD34-positive cell collection and DNA extraction. We collected CD34-positive cells from the marrow of DCL patients before treatment. Mononuclear cells were separated from $4 \mathrm{ml}$ of marrow by differential centrifugation over a
Ficoll-Paque PLUS gradient (GE Healthcare Biosciences), and purified CD34 cells were obtained by using the CD34 MicroBead kit UltraPure, human and MACS cell separation method (Miltenyi Biotec). DNA was extracted using the SepaGene DNA extraction kit (Sanko Junyaku).

Target sequencing for genetic mutations. We investigated driver mutations in 50 genes that were related to myeloid leukemia development in this DCL case by target gene sequencing analysis. Details of the 50 genes are described in supplementary Table SI. Over $500 \mathrm{ng}$ of DNA from CD34-positive cells was sequenced by multiplex PCR using GeneRead DNAseq Targeted Panels V2 [Human Myeloid Neoplasms (NGHS-003X)] (QIAGEN) according to the manufacturer's instructions. The DNA was sequenced using MiSeq (Illumina) with Reagent kit V2 in 151-base-pair (bp) paired-end reads. The average read depth of coverage was $1,500 x$ to allow for the detection of rare mutations and to accurately estimate variant allele frequencies (VAFs).

This analysis was approved by the Ethics Committee of Kawasaki Medical School (IRB no. 2408) (Kurashiki, China), and the patient provided written informed consent.

Variant data analysis. Alignment and variant calling were performed using the GeneRead targeted enrichment panel variant calling web service (http://ngsdataanalysis.sabiosciences.com). Original FASTQ files generated by MiSeq were uploaded into the web service, and then, we chose somatic workflow of the paired-end read mode. The workflow performed a variant filtering to reduce false positive variant calls. Single-nucleotide variants (SNVs) with $<4 \% \mathrm{VAF}$, as well as insertions and deletions (indels) with $<20 \%$ VAF, were removed. Functional annotations of the Ensembl database GRCh37.75 (25) and the possible effects of variants were added using SnpEff version 4.0E (26). Using these annotations, the workflow-passing variants were filtered first for those that were predicted to alter amino acid sequences (missense, nonsense, and splice-site mutations and indels in coding regions) and then for those that were rare $[<1.0 \%$ minor allele frequencies (MAF) in the HapMap-JPT (Japanese in Tokyo, Japan), the 1,000 Genomes EAS (the East Asian population including 104 Japanese individuals) or the Human Genetic Variation Database (HGVD, http://www.genome.med.kyoto-u. ac.jp/SnpDB/), which contained genetic variations determined by whole exome sequences (WES) in 1,208 Japanese individuals]. Target sequencing and data analysis were performed by Riken Genesis Co., Ltd.

Literature review. A literature review was conducted in PubMed and the Japan Medical Abstracts Society database using the terms 'donor cell leukemia' or 'donor cell-derived leukemia' from 2005 to 2018 . The papers were reviewed, and we reviewed cases of patients who developed DCL after CBT.

\section{Results}

Treatment after the development of DCL and outcomes of patients and cord blood donors. Our patient achieved CR after 3 cycles of azacytidine treatment and underwent a second allogenic CBT from an HLA-DR single-locus mismatch 
male donor. The reduced intensity conditioning regimen used fludarabine (40 mg/m²/day, 5 days), cyclophosphamide (50 mg/kg/day, 1 day) and 3 Gy of total body irradiation, and the GVHD prophylaxis included cyclosporine and mycophenolate mofetil. Favorable hematological recovery was observed on day +37 , and the patient was alive 5 years after the second $\mathrm{CBT}$ and remained in CR.

We followed up on the prognosis of the donor, and we confirmed that the donor was healthy when she was 1 year old, but her prognosis after that time was unknown.

Mutation analysis. Target sequencing revealed that DCL cells had genetic alterations in tet methylcytosine dioxygenase 2 (TET2) (S1107P) and additional sex combs like 1 (ASXL1) (E792D), which were novel nonsynonymous mutations (Table I). Another mutation of ASXL1 (E1028V) had never been reported in some databases but was discovered in the NCBI dbSNP database. Details of the sequence data are shown in supplementary Table SII.

\section{Discussion}

A total of 30 cases of donor cell-derived hematological malignancies after CBT were identified from 2005 to 2018 (Table II) $(6,12,14,27-52)$. The first reports of umbilical cord blood donor-derived leukemia were published by Fraser et al (12) and Matsunaga et al (14) in 2005. Seventeen of 31 cases, including our case, were female, and the median age of the patients was 33 years (range: 1-64 years). The median time from CBT to the development of DCL was 16 months (range: 2.6-60 months). The diagnosis of DCL was AML in 19 cases, MDS in 8 cases, ALL in 2 cases, chronic myeloproliferative disorder in 1 case and T-cell large granular lymphocyte leukemia in 1 case. The outcomes were described in 22 of the cases, and the median duration following donor cell-derived hematological malignancies was 8 months (range: 7 days-70 months). Fifteen of the patients were dead, 12 patients were alive at the time the reports were written, and 4 patients were not described. Twenty-one of the patients were treated with intensive therapy, and some recent cases were treated with demethylating agents (azacitidine or decitabine) or a Janus kinase inhibitor (tofacitinib). Finally, 7 patients had a second SCT, and 4 of those patients were alive. In contrast, 5 patients were alive out of 17 patients who were treated without SCT. The results of cytogenetic analyses were described in 27 cases, and the most frequent abnormalities, which were observed in 11 patients, involved chromosome 7. JT-DCL or AML were observed in 5 patients (cases 2, 8, 15, and 25 were AML, and the present case was MDS, Table II). JT of 1q21 was only detected in 2 patients, including our patient (case 2 and the present case, Table II). Molecular abnormalities were described in 7 of the cases (cases 8, 20, 22, 25, 26, 27 and the present case, Table II). The most frequent abnormality was a nucleophosmin 1 (NPM1) mutation, which was observed in 3 patients. Additionally, some other gene mutations that are usually found in de novo MDS or AML were observed. Gene mutations were found in JT-DCL, including the rearrangement of the myeloid/lymphoid leukemia or mixed lineage leukemia (MLL) gene (case 8), mutations of the Janus kinase 2 (JAK2), checkpoint kinase 2 (CHEK2), Down syndrome cell adhesion molecule (DSCAM), and IKAROS family zinc finger (IKZF1) genes (case 25) and mutations of TET2 and ASXL1 (present case).

The incidence of DCL has been estimated to range from less than 1 to $6.6 \%$ of all transplantations (2-10), and the frequency of DCL is increasing due to the increase in the number of SCTs (15). Dietz et al (9) reported that the risk of DCL was similar between stem cell sources. In contrast, Kato et al (6) reported that the incidence of DCL after CBT was significantly higher than after transplantation from other stem cell sources. The authors assumed that the naive immune function of cord blood might influence the onset of DCL (6). Shiozaki et al (46) estimated that a high proliferation of cord blood cells may be sufficient for inducing replication errors or mutations in DNA. However, it is difficult to accurately estimate the incidence of DCL.

Umbilical cord blood-derived leukemia has several features that are different from other stem cell sources. Shiozaki et al (46) reported that, concerning the type of DCL, AML and MDS occurred more frequently after CBT, whereas AML and ALL were observed at a similar frequency after bone marrow transplantatio (BMT). In our review of DCL after CBT, AML and MDS were most frequently observed in 27 cases, but ALL was observed in only 2 cases. The median time to the development of DCL after CBT was 16 months in our reviewed cases. DCL occurred more quickly after CBT (14.5 months) than after BMT (36 months), and the timing was similar to the period in which infant leukemia occurs with the highest incidence (46). The prognosis of DCL is generally poor, and 15 of 27 patients died of DCL progression or complications accompanying treatment. The median duration of follow-up in 22 cases of DCL after CBT was 8 months. The survival ratio of DCL patients who were not treated with SCT was lower than that of patients who were treated with SCT (5/17 patients, $29 \%$ vs. $4 / 7$ patients, $57 \%$, respectively). Our present patient is in CR 5 years after the second SCT, which is the longest surviving case in our reviewed reports. SCT seems to be an effective treatment for patients with DCL after CBT. Recently, DCL patients who were treated with novel drugs, such as demethylating agents or a Janus kinase inhibitor, have been reported. Although the prognosis of DCL is poor, our case obtained long-term survival by treatment with demethylating agents and subsequent SCT. This result suggests that the prognosis of DCL may improve by treatment with demethylating agents and subsequent transplantation. Obviously, it is necessary to consider in many cases in the future.

Regarding the karyotypes of DCL after CBT, the frequency of a normal karyotype was slightly lower than that seen after BMT (46). A normal karyotype was only seen in 6 out of 27 cases in our review. These results suggest that chromosomal abnormalities may play an important role in the development of DCL after CBT. The most frequent abnormalities involved chromosome 7 (11/27 cases, 41\%). Moreover, we found 5 cases with JT chromosomal abnormalities (5/27 cases, 19\%). JTs are very rare cytogenetic phenomena in de novo leukemia and MDS; however, JT abnormalities were observed frequently in patients with DCL after CBT. As far as we investigated, the frequency of JT in other stem cell sources was lower than that of CBT. Hertenstein et al (3) reported 14 cases of DCL in a survey of the European Group for Blood and Marrow Transplantation 


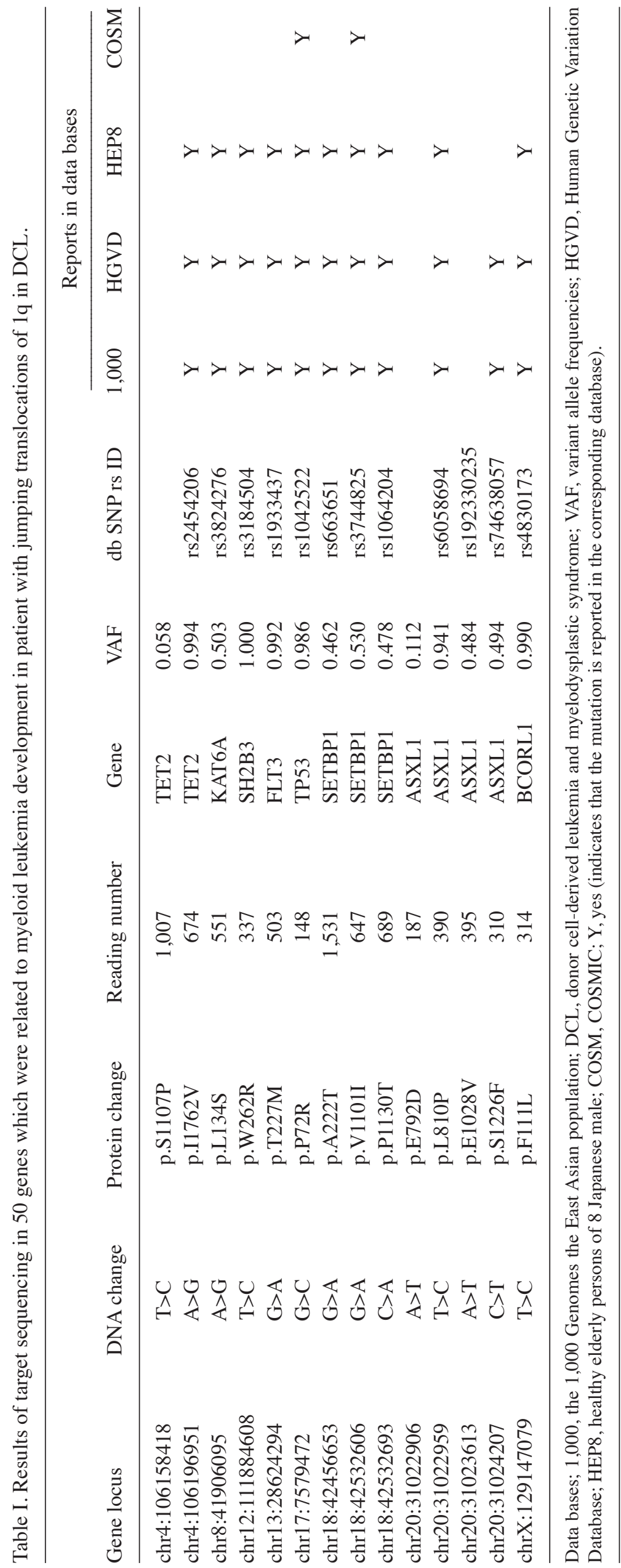




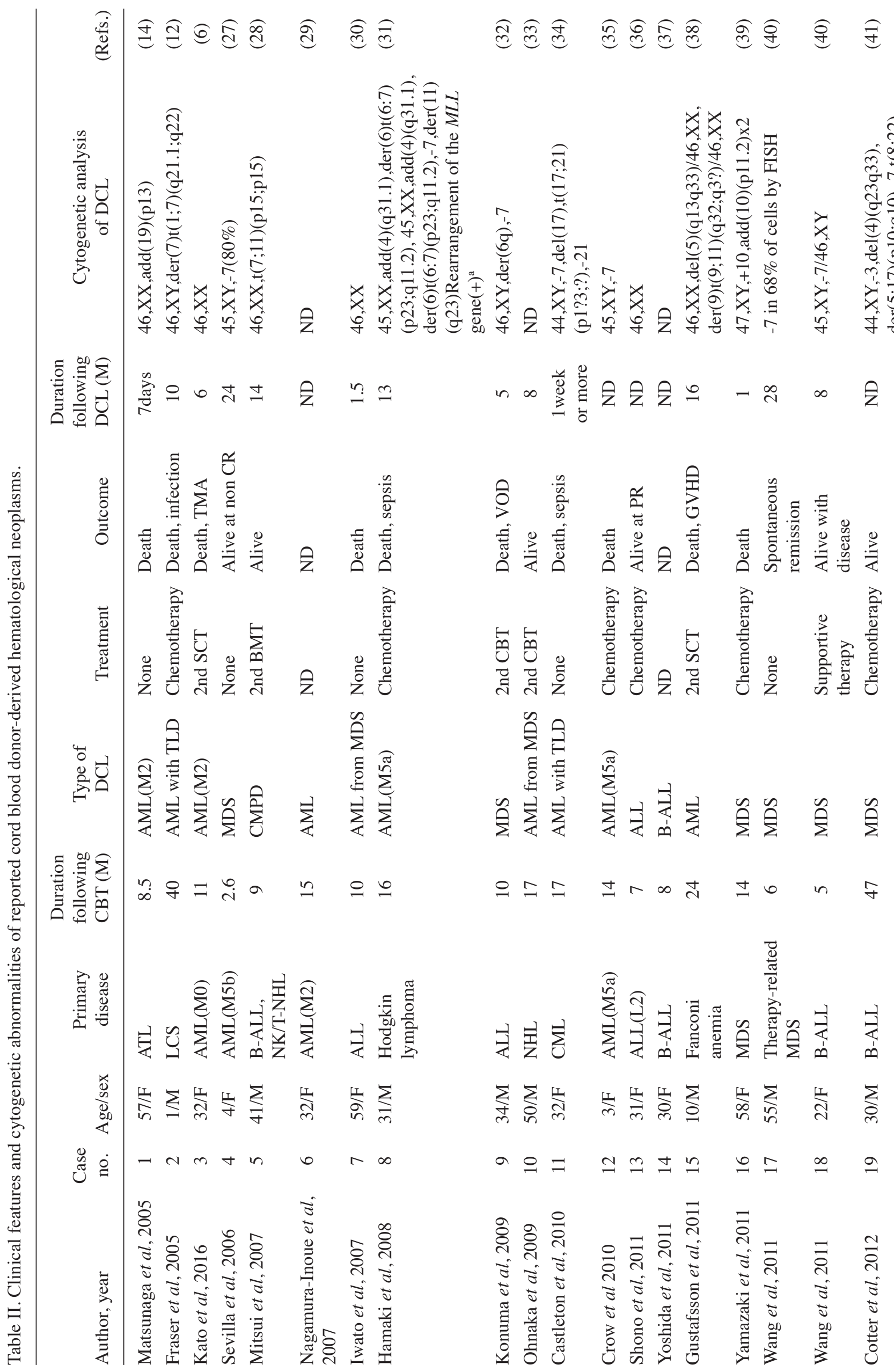




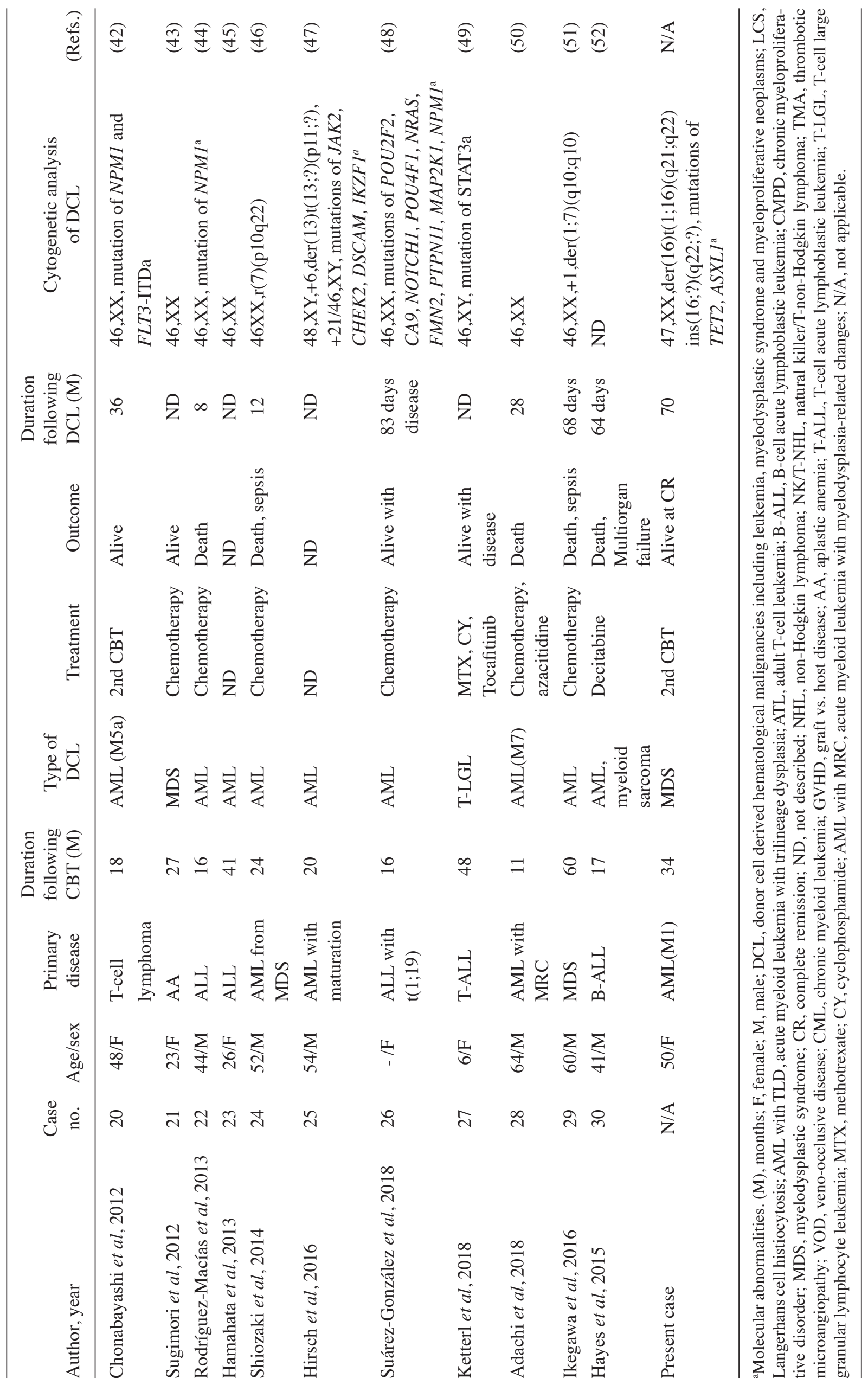


(EBMT); 12 donor sources were bone marrow and 2 were peripheral blood, but JT was not observed. Shiozaki et al (46) reported the results of comparing the features of DCL cases following BMT and CBT. In that report, JT was observed in 4 of 24 cases of DCL after CBT but not in 52 cases of DCL after BMT (27). From these limited results, JT abnormalities seemed to be an important mechanism underlying the development of DCL after CBT.

Recent studies revealed that several genetic mutations were found in de novo MDS or leukemia patients harboring JTs. Yeung et al (22) investigated genetic mutations in 6 cases of JT-MDS patients by using target gene panel next-generation sequencing. They reported that TET2 mutations were the most frequently observed mutations in their patients (4 of 6 JT-MDS patients), and $S F 3 B 1$ and $A S X L 1$ mutations were found in 3 and 2 patients with JT-MDS, respectively. These mutations were the most frequently observed in de novo MDS patients. We found genetic mutations of TET2 and ASXL1 in umbilical cord blood-derived JT-MDS. TET2 mutations have clearly been linked to myeloid dysfunction (53), clonal diseases such as MDS (54), and responsiveness to hypomethylating agents such as azacitidine or decitabine (55). Additionally, TET2 mutation results in an unstable genomic state and, when present in association with JTs, indicates a poor prognosis (22). Additionally, the ASXL1 mutation is associated with MDS development and disease progression (55). From these results, it was seemed that genetic alterations and subsequent additional chromosomal abnormalities such as JTs can lead to MDS, as in our present case.

In conclusion, we treated a JT-DCL patient who developed after CBT. Target sequencing analysis in our case and a review of previously reported DCL cases suggested that genetic mutations that are observed in de novo MDS and AML and not only chromosome 7 abnormalities but also JT chromosomal abnormalities are important for the development of DCL following CBT. The lengthy survival of our patient suggests that demethylating agents such as azacitidine and SCT may be effective as DCL treatment strategies. However, there are limited reports that analyze the molecular abnormalities and clinical features of JT-DCL. Further molecular analysis to understand the genetic alterations that cause JTs may facilitate targeted therapy for umbilical cord blood-derived JT-DCL.

\section{Acknowledgements}

Not applicable.

\section{Funding}

No funding was received.

\section{Availability of data and materials}

All data generated or analyzed during this study are included in this published article.

\section{Authors' contributions}

TK designed the research, acquired clinical data, analyzed genetic mutations and wrote the manuscript. TT designed the research, executed the study, analyzed the clinical data and wrote the manuscript. RS, KH, SY, HF, TH, AT, FS, HT, YM and HW acquired and analyzed the clinical data. All authors read and approved the final manuscript.

\section{Ethics approval and consent to participate}

This study was approved by the Institutional Review Board of Kawasaki Medical School (Kurashiki, Japan) and the patient provided written informed consent.

\section{Patient consent for publication}

The patient provided consent for publication of the data.

\section{Competing interests}

The authors declare that they have no competing interests.

\section{References}

1. Fialkow PJ, Thomas ED, Bryant JI and Neiman PE: Leukaemic transformation of engrafted human marrow cells in vivo. Lancet 1: 251-255, 1971 .

2. Sala-Torra O, Hanna C, Loken MR, Flowers ME, Maris M, Ladne PA, Mason JR, Senitzer D, Rodriguez R, Forman SJ, et al: Evidence of donor-derived hematologic malignancies after hematopoietic stem cell transplantation. Biol Blood Marrow Transplant 12: 511-517, 2006.

3. Hertenstein B, Hambach L, Bacigalupo A, Schmitz N McCann S, Slavin S, Gratwohl A, Ferrant A, Elmaagacli A, Schwertfeger R, et al: Development of leukemia in donor cells after allogeneic stem cell transplantation-a survey of the European group for blood and marrow transplantation (EBMT). Haematologica 90: 969-975, 2005.

4. Boyd CN, Ramberg RC and Thomas ED: The incidence of recurrence of leukemia in donor cells after allogeneic bone marrow transplantation. Leuk Res 6: 833-837, 1982.

5. Ballen KK, Cutler C, Yeap BY, McAfee SL, Dey BR, Attar EC, Chen YB, Haspel RL, Liney D, Koreth J, et al: Donorderived second hematologic malignancies after cord blood transplantation. Biol Blood Marrow Transplant 16: 1025-1031, 2010.

6. Kato M, Yamashita T, Suzuki R, Matsumoto K, Nishimori H, Takahashi S, Iwato K, Nakaseko C, Kondo T, Imada K, et al: Donor cell-derived hematological malignancy: A survey by the Japan society for hematopoietic cell transplantation. Leukemia 30: 1742-1745, 2016.

7. Wiseman DH: Donor cell leukemia: A review. Biol Blood Marrow Transplant 17: 771-789, 2011.

8. Gondek LP, Zheng G, Ghiaur G, DeZern AE, Matsui W, Yegnasubramanian S, Lin MT, Levis M, Eshleman JR, Varadhan $\mathrm{R}$, et al: Donor cell leukemia arising from clonal hematopoiesis after bone marrow transplantation. Leukemia 30: 1916-1920, 2016.

9. Dietz AC, DeFor TE, Brunstein CG and Wagner JE Jr: Donor-derived myelodysplastic syndrome and acute leukaemia after allogeneic haematopoietic stem cell transplantation: Incidence, natural history and treatment response. $\mathrm{Br} \mathrm{J}$ Haematol 166: 209-212, 2014.

10. Murata M, Ishikawa Y, Ohashi H, Terakura S, Ozeki K, Kiyoi H and Naoe T: Donor cell leukemia after allogeneic peripheral blood stem cell transplantation: A case report and literature review. Int J Hematol 88: 111-115, 2008.

11. Reichard KK, Zhang QY, Sanchez L, Hozier J, Viswanatha D and Foucar K: Acute myeloid leukemia of donor origin after allogeneic bone marrow transplantation for precursor T-cell acute lymphoblastic leukemia: Case report and review of the literature. Am J Hematol 81: 178-185, 2006.

12. Fraser CJ, Hirsch BA, Dayton V, Creer MH, Neglia JP, Wagner JE and Baker KS: First report of donor cell-derived acute leukemia as a complication of umbilical cord blood transplantation. Blood 106: 4377-4380, 2005. 
13. Ando T, Yujiri T, Mitani N, Takeuchi H, Nomiyama J, Suguchi M Matsubara A and Tanizawa Y: Donor cell-derived acute myeloid leukemia after unrelated umbilical cord blood transplantation. Leukemia 20: 744-745, 2006

14. Matsunaga T, Murase K, Yoshida M, Fujimi A, Iyama S, Kuribayashi K, Sato T, Kogawa K, Hirayama Y, Sakamaki S, et al: Donor cell derived acute myeloid leukemia after allogeneic cord blood transplantation in a patient with adult T-cell lymphoma. Am J Hematol 79: 294-298, 2005.

15. Engel N, Rovo A, Badoglio M, Labopin M, Basak GW, Beguin Y, Guyotat D, Ljungman P, Nagler A, Schattenberg A, et al: European experience and risk factor analysis of donor cell-derived leukaemias/MDS following haematopoietic cell transplantation. Leukemia 33: 508-517, 2019.

16. Dickson MA, Papadopoulos EB, Hedvat CV, Jhanwar SC and Brentjens RJ: Acute myeloid leukemia arising from a donor derived premalignant hematopoietic clone: A possible mechanism for the origin of leukemia in donor cells. Leuk Res Rep 3: 38-41, 2014.

17. Wynn RF, Cross MA, Hatton C, Will AM, Lashford LS, Dexter TM and Testa NG: Accelerated telomere shortening in young recipients of allogeneic bone-marrow transplants. Lancet 351: 178-181, 1998.

18. Flynn CM and Kaufman DS: Donor cell leukemia: Insight into cancer stem cells and the stem cell niche. Blood 109: 2688-2692, 2007.

19. Suárez-González J, Martínez-Laperche C, Kwon M, Balsalobre P, Carbonell D, Chicano M, Rodríguez-Macías G, Serrano D, Gayoso J, Díez-Martín JL and Buño I: Donor cell-derived hematologic neoplasms after hematopoietic stem cell transplantation: A systematic review. Biol Blood Marrow Transplant 24 1505-1513, 2018.

20. Berger R and Bernard OA: Jumping translocations. Genes Chromosomes Cancer 46: 717-723, 2007.

21. Shaffer LG, McGowan-Jordan J and Schmid M (eds): ISCN 2013: An international system for human cytogenetic nomenclature. Karger 140, 2013.

22. Yeung CCS, Deeg HJ, Pritchard C, Wu D and Fang M: Jumping translocations in myelodysplastic syndromes. Cancer Genet 209 $395-402,2016$

23. Couture T, Amato K, DiAdamo A and Li P: Jumping translocations of 1q in myelodysplastic syndrome and acute myeloid leukemia: Report of three cases and review of literature. Case Rep Genet 2018: 8296478, 2018.

24. Sanford D, DiNardo CD, Tang G, Cortes JE, Verstovsek S, Jabbour E, Ravandi F, Kantarjian H and Garcia-Manero G: Jumping translocations in myeloid malignancies associated with treatment resistance and poor survival. Clin Lymphoma Myeloma Leuk 15: 556-562, 2015.

25. Flicek P, Amode MR, Barrell D, Beal K, Billis K, Brent S, Carvalho-Silva D, Clapham P, Coates G, Fitzgerald S, et al: Ensembl 2014: Nucleic Acids Res 42 (Database Issue): D749-D755, 2014

26. Cingolani P, Platts A, Wang le L, Coon M, Nguyen T, Wang L, Land SJ, Lu X and Ruden DM: A program for annotating and predicting the effects of single nucleotide polymorphisms, SnpEff: SNPs in the genome of Drosophila melanogaster strain w1118; iso-2; iso-3. Fly (Austin) 6: 80-92, 2012.

27. Sevilla J, Querol S, Molines A, González-Vicent M, Balas A, Carrió A, Estella J, Angel Díaz M and Madero L: Transient donor cell-derived myelodysplastic syndrome with monosomy 7 after unrelated cord blood transplantation. Eur J Haematol 77 259-263, 2006

28. Mitsui H, Nakazawa T, Tanimura A, Karasuno T and Hiraoka A: Donor cell-derived chronic myeloproliferative disease with $t(7 ; 11)(p 15 ; p 15)$ after cord blood transplantation in a patient with Philadelphia chromosome-positive acute lymphoblastic leukemia. Int J Hematol 86: 192-195, 2007.

29. Nagamura-Inoue T, Kodo $\mathrm{H}$, Takahashi TA, Mugishima $\mathrm{H}$, Tojo A and Asano S: Four cases of donor cell-derived AML following unrelated cord blood transplantation for adult patients: Experiences of the Tokyo cord blood bank. Cytotherapy 9: 727-728, 2007

30. Iwato K, Katayama Y, Nagoshi H, Ota I, Yuasa H, Asaoku H and Kyo T: Donor cell derived AML after cord blood transplantation in a patient with refractory all. Jpn J Clin Hematol 48: 1168, 2007.

31. Hamaki T, Kajiwara K, Kami M, Murashige N, Funaki M, Harima A, Kogure K, Yamada K, Kodo H and Kouzai Y: Donor cell-derived acute monoblastic leukemia involving MLL gene translocation in an adult patient who received umbilical cord blood transplantation. Bone Marrow Transplant 41: 91-92, 2008
32. Konuma T, Ooi J, Takahashi S, Tomonari A, Tsukada N, Kato S, Sato A, Monma F, Hongo E, Uchimaru K, et al: Donor cell derived myelodysplastic syndrome after cord blood transplantation. Bone Marrow Transplant 43: 429-431, 2009.

33. Ohnaka T, Yonezawa S and Imada K: A case of donor cell leukemia following cord blood transplantation for recurrent follicular lymphoma underwent second cord blood transplantation. The 31st Annual Meeting of the Japan society for Hematopoietic Cell Transplantation. 2009;186: (abstract in Japanese). https://www. jshct.com $/$ modules/basicauth2/index.php?file $=$ jshctam31.pdf.

34. Castleton AZ, Brazma D, Howard-Reeves J, Chanalaris A, Glanville J, Nizetic D, Chakraverty R and Nacheva EP: Genome gains at chromosome 21q21/22 segment leads to co-amplification of down syndrome critical regions and known oncogenes in a case of donor cell-derived acute myeloid leukemia following allogeneic sex mismatched umbilical cord blood transplantation for chronic myeloid leukemia. Br J Haematol 151: 285-288, 2010.

35. Crow J, Youens K, Michalowski S, Perrine G, EmhartC, Johnson F, Gerling A, Kurtzberg J, Goodman BK, Sebastian S, et al: Donor cell leukemia in umbilical cord blood transplant patients: A case study and literature review highlighting the importance of molecular engraftment analysis. J Mol Diag 12: 530-537, 2010.

36. Shono Y, Kosugi-Kanaya M, Shiratori S, Sugita J, Fujimoto K, Kondo T, Nishio M, Tanaka J and Imamura M: Donor cell leukemia after umbilical cord blood transplantation: Recurrent or de novo? The importance of diagnosis for therapeutic decision making. Int J Hematol 93: 563-565, 2011.

37. Yoshida M, Takemura R, Kosugi M, Shiratori S, Shono Y, Takeda M, Sugita J, Fujimoto K, Nishio M, et al: Donor cell leukemia after umbilical cord blood transplantation. Jpn J Clin Hematol 52: 1241, 2011

38. Gustafsson B, Moell J, LeBlanc K, Barbany G, Söderhäll S and Winiarski J: Donor cell-derived acute myeloid leukemia after second allogenic cord blood transplantation in a patient with Fanconi anemia. Pediatr Transplant 16: E241-E245, 2012.

39. Yamazaki R, Nakasone H, Wada H, Sakamoto K, Ashizawa M, Sato M, Terasako K, Kikuchi M, Kimura S, Okuda S, et al: Recurrence of monoclonal gammopathy associated with donor-derived myelodysplastic syndrome after cord blood stem cell transplantation. Exp Hematol 39: 1119-1123, 2011.

40. Wang E, Hutchinson CB, Huang Q, Lu CM, Crow J, Wang FF, Sebastian S, Rehder C, Lagoo A, Horwitz M, et al: Donor cell-derived leukemias/myelodysplastic neoplasms in allogeneic hematopoietic stem cell transplant recipients. A clinicopathologic study of 10 cases and a comprehensive review of the literature. Am J Clin Pathol 135: 525-540, 2011.

41. Cotter R, Najfeld V, Isola L, Toro GD, Roman E, Peterson B and Mascarenhas J: An unusual case of donor-derived myelodysplastic syndrome following double-unit umbilical cord blood transplantation in acute lymphoblastic leukemia. Am J Hematol 9: 931-933, 2012.

42. Chonabayashi K, Kondo T, Yamamoto K, Tanaka Y, Nagai Y, Hishizawa M and Takaori-Kondo A: Successful use of second cord blood transplantation to achieve long-term remission in cord blood donor cell-derived AML harboring a FLT3-ITD and an NPM1 mutation. Bone Marrow Transplant 47: 1252-1253, 2012.

43. Sugimori C, Yoshida A, Munemoto S, Zaimoku Y, Sawazaki A, Yamaguchi $M$ and Ueda $M$ : Donor-type myelodysplastic syndrome after cord blood transplant in a patient with aplastic anemia. Jpn J Clin Hematol 53: 1277, 2012.

44. Rodríguez-Macías G, Martínez-Laperche C, Gayoso J, Noriega V, Serrano D, Balsalobre P, Muñoz-Martínez C, Díez-Martín JL and Buño I: Mutation of the NPM1 gene contributes to the development of donor cell-derived acute myeloid leukemia after unrelated cord blood transplantation for acute lymphoblastic leukemia. Human Pathol 44: 1696-1699, 2013.

45. Hamahata K, Kotani S, Oka S, Ukyo N, Watanabe N and Nogawa M: Development of donor cell leukemia mimicking hematogones after unrelated cord blood transplantation for relapsed acute lymphoblastic leukemia. Rinsho Ketsueki 54: 473-477, 2013 (In Japanese).

46. Shiozaki H, Yoshinaga K, Kondo T, Imai Y, Shiseki M, Mori N, Teramura $\mathrm{M}$ and Motoji T: Donor cell-derived leukemia after cord blood transplantation and a review of the literature: Differences between cord blood and BM as the transplant source. Bone Marrow Transplant 49: 102-109, 2014.

47. Hirsch P, Mamez AC, Belhocine R, Lapusan S, Tang R, Suner L, Bories D, Marzac C, Fava F, Legrand O, et al: Clonal history of a cord blood donor cell leukemia with prenatal somatic JAK2 V617F mutation. Leukemia 30: 1756-1759, 2016 
48. Suárez-González J, Martínez-Laperche C, Martínez N, Rodríguez-Macías G, Kwon M, Balsalobre P, Carbonell D, Chicano M, Serrano D, Triviño JC, et al: Whole-exome sequencing reveals acquisition of mutations leading to the onset of donor cell leukemia after hematopoietic transplantation: A model of leukemogenesis. Leukemia 32: 1822-1826, 2018.

49. Ketterl TG, Wu D, Fromm JR, Soma L, Dahlberg AE, Wood BL and Tarlock K: Donor derived T-cell large granular lymphocyte leukemia after cord blood transplant for pediatric T-cell lymphoblastic leukemia. Bone Marrow Transplant 53: 352-355, 2018.

50. Adachi Y, Yamaguchi Y, Sagou K, Yamaga Y, Fukushima N, Ozeki K and Kohno A: Acute megakaryoblastic leukemia developing as donor cell leukemia after umbilical cord blood transplantation. Intern Med 57: 569-574, 2018.

51. Ikegawa S, Najima Y, Sano N, Horiguchi SI, Kaito S, Kurosawa S, Sakaguchi M, Harada K, Hino Y, Yamamoto K, et al: Donor cell leukemia with bone marrow necrosis. Rinsho Ketsueki 57: 2334-2338, 2016 (In Japanese).
52. Hayes C, Petersen B and Malone A: Donor cell myeloid sarcoma in an umbilical cord transplant patient: A case report and a review of the literature. Case Rep Hematol 2015: 186869, 2015.

53. Scopim-Ribeiro R, Machado-Neto JA, Campos Pde M, Silva CA, Favaro P, Lorand-Metze I, Costa FF, Saad ST and Traina F: Ten-eleven-translocation 2 (TET2) is downregulated in myelodysplastic syndromes. Eur J Haematol 94: 413-418, 2015.

54. Zhang W, Shao ZH, Fu R, Wang HQ, Li LJ, Wang J, Qu W, Liang Y, Wang GJ, Wang XM, et al: TET2 expression in bone marrow mononuclear cells of patients with myelodysplastic syndromes and its clinical significances. Cancer Biol Med 9: 34-37, 2012.

55. Bejar R, Lord A, Stevenson K, Bar-Natan M, Pérez-Ladaga A, Zaneveld J, Wang H, Caughey B, Stojanov P, Getz G, et al: TET2 mutations predict response to hypomethylating agents in myelodysplastic syndrome patients. Blood 124: 2705-2712, 2014. 